\title{
Microstructural Stability of a Niobium Single Crystal Deformed by Equal Channel Angular Pressing
}

\author{
Heide Heloise Bernardi ${ }^{a, b *}$, Hugo Ricardo Zschommler Sandim ${ }^{a}$, Kahl Dick Zilnykc, Bert Verlinden ${ }^{d}$, \\ Dierk Raabe \\ ${ }^{a}$ Escola de Engenharia de Lorena, Universidade de São Paulo (USP), 12600-970, Lorena, SP, Brazil \\ ${ }^{b}$ Faculdade de Tecnologia de São José dos Campos, Prof. Jessen Vidal - FATEC-SJC, 12247, \\ São José dos Campos, SP, Brazil \\ 'Instituto Federal de Educação, Ciência e Tecnologia de São Paulo, 18202-000, Itapetininga, SP, Brazil \\ ${ }^{d}$ Department of Materials Engineering, Katholieke Universiteit Leuven 3001, Leuven, Belgium \\ ${ }^{e}$ Max-Planck-Institut für Eisenforschung D-40237, Düsseldorf, Germany
}

Received: March 15, 2017; Revised: June 13, 2017; Accepted: June 20, 2017

\begin{abstract}
A [211]-oriented niobium single crystal was deformed by equal channel angular pressing (ECAP) at room temperature using the route $\mathrm{B}_{\mathrm{c}}$ to a total strain of 9.2. A sharp cube texture develops after ECAP processing. The deformed samples were annealed in vacuum from $400^{\circ} \mathrm{C}(673 \mathrm{~K})$ to $900^{\circ} \mathrm{C}$ $(1173 \mathrm{~K})$ for $1 \mathrm{~h}$ to evaluate their microstructural stability. Scanning electron microscopy (SEM) was used to image the microstructures of as-deformed and annealed specimens. Electron backscatter diffraction (EBSD) was employed to determine the respective microtextures before and after annealing. Coarsening of the microstructure occurs at a maximum rate at $550^{\circ} \mathrm{C}(823 \mathrm{~K})$ due to discontinuous recrystallization. Normal grain growth replaces discontinuous recrystallization as the main coarsening mechanism above $700^{\circ} \mathrm{C}(973 \mathrm{~K})$.
\end{abstract}

Keywords: Niobium, recrystallization, grain growth, ECAP, EBSD

\section{Introduction}

Niobium is an important material for several engineering applications in many environments and within a wide range of temperatures. It has a body-centered cubic (BCC) structure and displays interesting properties such as a very high melting point combined with modest mass density, high ductility, good biocompatibility, and good corrosion resistance. However, high-purity niobium is very soft which hinders its application in many situations where higher mechanical strength is needed and alloying must be avoided. Grain refinement provided by severe plastic deformation (SPD) techniques such as equal channel angular pressing (ECAP) is a suitable alternative to increase its mechanical strength.

ECAP (also termed ECAE - Equal Channel Angular Extrusion) promotes intensive microstructural refinement, yielding materials with grain sizes below $1 \mu \mathrm{m}$ (ultrafinegrained structure) and unique mechanical properties. This SPD technique has been gaining more importance and it is already performed on industrial scale to yield high-strength materials such as precipitation-hardening aluminum alloys for aerospace applications ${ }^{1}$ and more recently unalloyed titanium for orthopedic implants ${ }^{2}$. First industrial applications of SPD technique was the manufacture of sputtering targets. Materials such as aluminum, copper and titanium high purity, with submicron grain sizes deformed by ECAP, are being applied in the electronics industry as sputtering targets ${ }^{1,3,4}$.

The microstructural refinement is accomplished by severe plastic deformation during multiple passes ${ }^{5}$. During ECAP, a billet is pressed through a die with two intersecting channels of the same cross section that meet at an angle $\varphi^{6-8}$. The predominant deformation mechanism is simple shear and occurs parallel to the intersecting plane of the channels ${ }^{9-11}$. A comprehensive review about this technique can be found elsewhere ${ }^{8}$.

The formation of ultrafine-grained (UFG) structures during ECAP requires the creation of a large fraction of high angle boundaries (HAB) within the deformed structure. Grain refinement promotes the increase of the mechanical strength (Hall-Petch mechanism) in UFG materials. On the other hand, most severely deformed materials exhibit low ductility and must be annealed to obtain an optimum balance of the mechanical properties ${ }^{12-14}$. Prangnell et al. ${ }^{15}$ have reported that the presence of a significant fraction of HABs within the deformation structure, e.g. $>70 \%$, could lead to continuous recrystallization of the material, or grain growth, rather than discontinuous recrystallization ${ }^{16}$. Moreover, Humphreys et al. ${ }^{17}$ have demonstrated that, in principle, a cellular structure will become resistant to discontinuous growth when the volume fraction of high-angle grain boundaries is larger than about $70 \%$.

* e-mail: heide.bernardi@fatec.sp.gov.br 
The discussion about the exact value where continuous recrystallization displaces discontinuous recrystallization as the main softening mechanism in ECAP-processed materials is not the aim of the present work, also because these characteristics not only depends on the HABs, but also on other properties such as crystalline structure, composition, stacking fault energy (SFE), ECAP processing route, and so on.

The knowledge of the underlying mechanisms responsible for the softening that occurs during isothermal annealing of ECAP-processed materials is essential to set the operating limits for their application at moderate-to-high temperatures; i.e. the evaluation of its microstructural stability. Nevertheless, most of the literature discusses the recrystallization behavior of face-centered cubic (FCC) materials, particularly $\mathrm{Al}, \mathrm{Cu}$, and Ni. Only a few works report on the microstructural evolution of body-centered cubic (BCC) during annealing so far ${ }^{18-22}$. In the case of BCC single crystals processed by ECAP, in especial niobium single crystal $^{23}$, the number of reported studies is certainly even smaller.

This paper reports the main results about the annealing behavior of a niobium single crystal deformed by 8 ECAP passes using the route $\mathrm{B}_{\mathrm{c}}$ to evaluate its thermal (microstructural) stability. Results show that the microstructure coarsens by discontinuous recrystallization in the range of $500^{\circ} \mathrm{C}-700^{\circ} \mathrm{C}$ (773 K-973 K). Above this temperature, normal grain growth replaces discontinuous recrystallization as the main coarsening mechanism in ECAP-processed niobium.

\section{Experimental}

A niobium single crystal oriented with the [211] direction parallel to the punching direction was carefully cut out from a high-purity coarse-grained ingot processed by multiple electron beam melting to get cylindrical billets with diameter of $12 \mathrm{~mm}$ and length of $50 \mathrm{~mm}$. This particular orientation was obtained by coincidence. The chemical composition of this material is given in Table 1. The sample was processed at room temperature using the route $\mathrm{B}_{\mathrm{c}}$, for more details about processing are given in refs. ${ }^{23,24}$.

Table 1. Chemical composition of the niobium single crystal expressed in ppm-wt.

\begin{tabular}{cccc}
\hline $\mathrm{O}$ & $\mathrm{N}$ & $\% \mathrm{C}$ & $\mathrm{S}$ \\
\hline $44 \pm 42$ & $<30$ & $64 \pm 20$ & $<20$ \\
\hline
\end{tabular}

As-pressed samples were cut out and annealed in vacuum from $400^{\circ} \mathrm{C}(673 \mathrm{~K})$ to $900^{\circ} \mathrm{C}(1173 \mathrm{~K})$ for 1 hour holding time at each temperature to evaluate their thermal stability. The microstructure was imaged using a JEOL-6500F field emission gun scanning electron microscope (FEG-SEM) operating at $15 \mathrm{kV}$. Microtexture and mesotexture data were obtained by automated acquisition and further indexing of Kikuchi patterns after image processing in a TSL system interfaced to the SEM. All EBSD maps were carried out in the central part of the specimens using a step size of $50 \mathrm{~nm}$. Points with confidence index (CI) below 0.1 were removed from the dataset. Vickers microhardness testing was performed in longitudinal and cross sections of the specimens using a load of $50 \mathrm{~g}$ for $30 \mathrm{~s}$. Grain size and boundary spacing were determined by the linear intercept method (ASTM E112). EBSD analyses and the grain size (ASTM E112) were calculated in the transversal plane of the specimens, in other words, extrusion direction-normal direction (ED-ND), whereas the SEM micrograph (Figure 1) shows the extrusion plane (ND-TD).

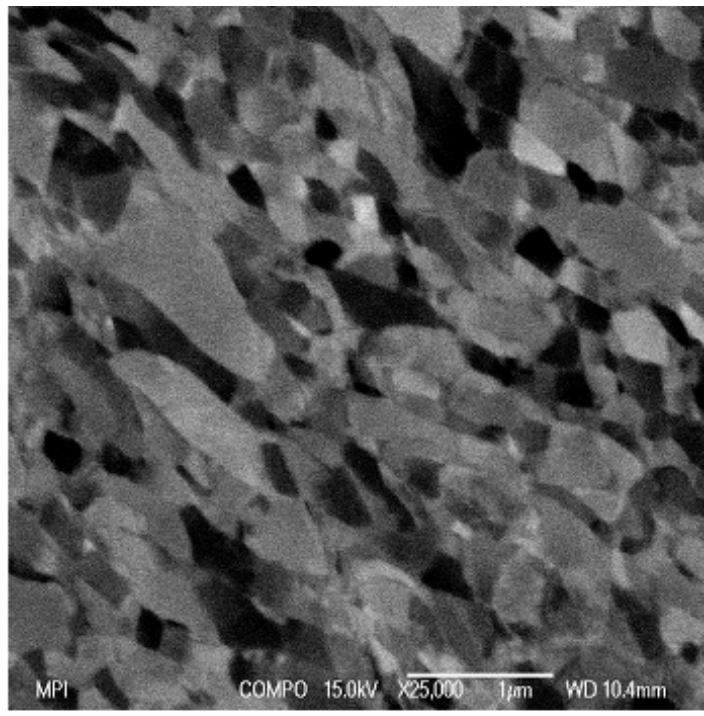

(b)

(a)

Figure 1. SEM micrographs of the niobium single crystal deformed by 8 ECAP passes (ND-TD section): (a) General view of the deformed structure and (b) Enlarged view of the rectangle show in (a). (ND: normal direction; TD: transversal direction). 


\section{Results and Discussion}

\subsection{Deformation microstructure}

The work hardening behavior of this niobium single crystal was evaluated by Vickers microhardness testing. Hardness varied from $78 \pm 1 \mathrm{HV}-0.05$ (single crystal) to $139 \pm 4 \mathrm{HV}-0.05$ after 8 ECAP passes. This pronounced work hardening can be explained by the multiplication and interaction of dislocations during severe deformation. Details of the as-worked microstructure of this particular $\mathrm{Nb}$ single crystal are given in ref. ${ }^{24}$.

Figure 1 shows the SEM micrograph of the cross section (TD-ND) of the as-worked material after 8 ECAP passes. The microstructure of heavily deformed materials can be described as being an aggregate of crystallites bounded by an unequal mixture of high and low angle boundaries. The deformation structure consists of fine crystallites arranged in a lamellar structure with sizes lower than $1 \mu \mathrm{m}$. This microstructure results of pronounced refinement promoted by ECAP as a result of the progressive subdivision of the crystal and further boundary refinement ${ }^{9-11,25}$. The volume fraction of $\mathrm{HABs}$ in ECAP-processed $\mathrm{Nb}$ after 8 passes was $48 \%$ and the average linear intercept distance between HABs was $0.33 \pm 0.03 \mu \mathrm{m}$, after a standard cleaning procedure to remove non-indexed points ${ }^{24}$. Etter et al. ${ }^{26}$ and Reihanian et al. ${ }^{27}$ have investigated the microstructure of high-purity polycrystalline copper and aluminum deformed by ECAP using the same route $\mathrm{B}_{\mathrm{c}}$. The average intercept distance between HABs was $0.4 \mu \mathrm{m}$ for copper and $0.38 \mu \mathrm{m}$ for aluminum. In spite of the differences in terms of stacking fault energy (SFE) of both metals, the results for niobium are rather similar in terms of the grain structure developed after 8 ECAP passes. Moreover, Pan et al. ${ }^{28}$ studying commercialpurity niobium polycrystalline up to 8 ECAP passes using route $\mathrm{E}$ obtained an average grain size of $0.30 \mu \mathrm{m}$ and the volume fraction of HABs was $50 \%$, amounts very consistent with those obtained in this study.

\subsection{Annealing behavior}

It is observed a softening pronounced between $500^{\circ} \mathrm{C}(773$ $\mathrm{K})$ and $600^{\circ} \mathrm{C}(873 \mathrm{~K})$. This behavior is commonly found in materials such as undergoing discontinuous recrystallization. The volume fraction of HABs increases significantly in that temperature range. It reaches about $85 \%$ after annealing at $600^{\circ} \mathrm{C}(873 \mathrm{~K})$ where discontinuous recrystallization is almost complete. Therefore, the steep increase observed when the volume fraction of HABs is plotted against the annealing temperature (Figure $2 \mathrm{a}$ ) as well the pronounced concurrent softening, can be attributed to the occurrence of discontinuous recrystallization. HABs increase significantly with temperature during annealing when recrystallization occurs in a discontinuous manner ${ }^{29}$. The volume fraction of HABs in the as-deformed material is about $48 \%{ }^{24}$. It is worth mentioning that this large density of high-angle boundaries contributes to an increase in the stored energy in the deformed state, providing an additional driving force for grain coarsening. It is worth mentioning that the existing high angle grain boundaries act as additional excellent nucleation centers for primary recrystallization. According to the estimates made by several authors ${ }^{15,17}$, a volume fraction of HABs less than about $70 \%$ promotes discontinuous recrystallization and competitive grain coarsening during annealing. Mathaudhu et al. ${ }^{20}$ report about the evolution of the density of HABs in tantalum deformed by 4 ECAP passes (route $\mathrm{B}_{\mathrm{c}}$ ). This material is similar to niobium in certain properties ${ }^{30}$. It was observed that the tantalum billet exhibited partial recrystallization, and this phenomenon occurred initially in the regions containing deformation inhomogeneities (banded areas).

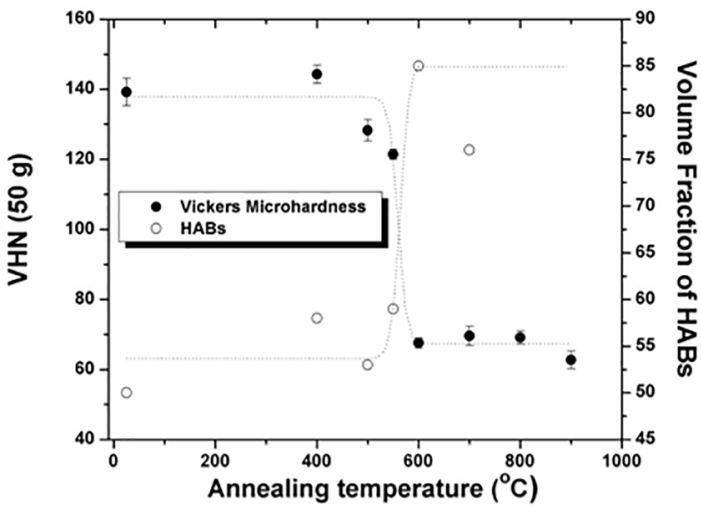

(a)

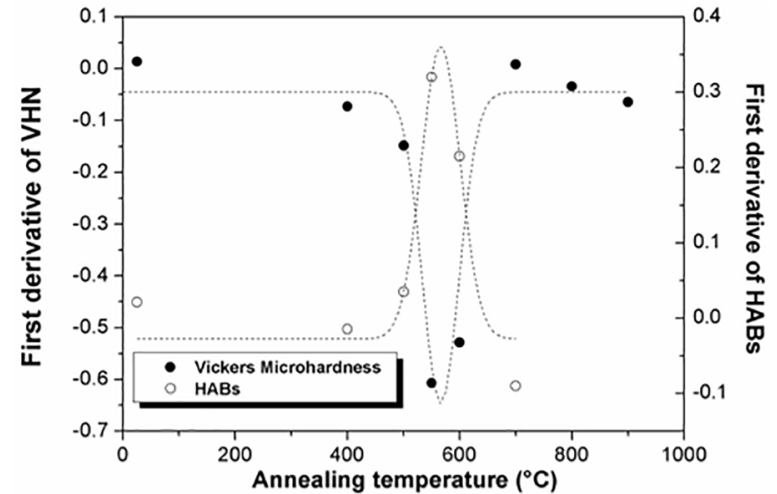

(b)

Figure 2. (a) Changes in the volume fraction of high angle boundaries and softening behavior during one hour isothermal annealing in a niobium single crystal deformed by 8 ECAP passes and (b) First derivative of these microstructural properties to demonstrate that $550^{\circ} \mathrm{C}(823 \mathrm{~K})$ is the temperature where softening reaches a maximum due to discontinuous recrystallization. The dotted line represents fit experimental points (Gaussian Functions). 
The first derivatives of the data depicted in Figure 2 are shown in Figure 2b. The maximum variation of the Vickers microhardness and volume fraction of HABs takes place at about $550^{\circ} \mathrm{C}(823 \mathrm{~K})$. These results match those obtained from quantitative metallography inspection revealing that microstructural coarsening becomes noticeable at this temperature. Below this temperature, the HAB spacing is rather constant. The measured $\mathrm{HAB}$ spacing for samples annealed within a large temperature range is shown in Table 2. We have included the HAB spacing determined both parallel and perpendicular to the ED, to stress changes in grain shape. We find that the grain aspect ratio varies from 6 to 3 in the samples annealed for $1 \mathrm{~h}$ from $400^{\circ} \mathrm{C}(673 \mathrm{~K})$ up to $550^{\circ} \mathrm{C}$ $(823 \mathrm{~K})$, respectively. At higher annealing temperatures, the elongated microstructure evolves into an equiaxed grain structure with an aspect ratio of about 1 .

The EBSD analysis shows that different mechanisms take place depending on the annealing temperature. At $400^{\circ} \mathrm{C}(673 \mathrm{~K})$ static recovery is the predominant softening mechanism. The inverse pole figure (IPF) map of this sample (Figure 3a) shows elongated grains, similar to those found in the as-deformed state. Between $500^{\circ} \mathrm{C}(773 \mathrm{~K})$ and $550^{\circ} \mathrm{C}$ $(823 \mathrm{~K})$ a significant fraction of recrystallized grains can be seen in the microstructure (Figures $3 b$ and $3 c$ ). Because of the high-purity of the single crystal and the large amount of strain due to ECAP processing, niobium undergoes primary (discontinuous) recrystallization already at a very low homologous temperature; i.e. at about $0.28 \mathrm{~T}_{\mathrm{m}}$, where $\mathrm{T}_{\mathrm{m}}$ is the melting point in Kelvin $(2741 \mathrm{~K})$. In the IPF maps, they appear as small, equiaxed grains contrasting with the elongated morphology of non-recrystallized areas in the microstructure. The presence of these lamellar structures resulting from severe plastic deformation is evident in some areas, i.e. recrystallization is incomplete. Another important feature is the presence of banded areas where recovered and recrystallized areas coexist in the annealed structure.

Normal grain growth occurs in the microstructure of samples annealed at $700^{\circ} \mathrm{C}(973 \mathrm{~K})$ and above (Figure $\left.3 \mathrm{~d}\right)$. An important microstructure feature at this temperature and above is that the grain aspect ratio approaches 1 (Table 2). The grain size distribution is rather broad, mirroring the coexistence of small grains not yet consumed by coarser ones in the annealed microstructure.
The grain orientation spread (GOS) is determined as the average difference in orientation between each pixel inside a grain and the grain average orientation. Recrystallized grains have lower GOS values than deformed grains as reported in several papers ${ }^{31-35}$. In this work, a threshold value of $2.5^{\circ}$ was chosen to distinguish recrystallized and non-recrystallized grains. This threshold value is determined to distinguish a recrystallized grain from a recovered one, which implies that grains with GOS $<2.5^{\circ}$ are recrystallized ${ }^{31}$. The GOS distributions of four samples $\left(400^{\circ} \mathrm{C} / 673 \mathrm{~K}, 500^{\circ} \mathrm{C} / 773 \mathrm{~K}\right.$, $550^{\circ} \mathrm{C} / 823 \mathrm{~K}$ and $700^{\circ} \mathrm{C} / 973 \mathrm{~K}$ ) are compared to each other in Figure 4. A systematic trend of the reduction in the GOS value for higher annealing temperatures can be noticed indicating the progress in microstructure restoration.

In a GOS map, all pixels within a grain are shaded with the same color. In the grain orientation spread (GOS) maps corresponding to samples annealed at $500^{\circ} \mathrm{C}(773 \mathrm{~K})$ and $550^{\circ} \mathrm{C}(823 \mathrm{~K})$ (Figure 5a and $\left.5 \mathrm{~b}\right)$, the new recrystallized grains appear as regions with lower values of orientation spread. According to the GOS maps, the recrystallized volume fraction in the samples annealed at $500^{\circ} \mathrm{C}(773 \mathrm{~K})$ and $550^{\circ} \mathrm{C}$ $(823 \mathrm{~K})$ are about $35 \%$ and $61 \%$, respectively. The increase in the volume fraction of recrystallized grains matches the decrease in the fraction of LABs, since boundaries between recrystallized grains are most HABs. This discrete change with increasing temperatures is evidence that discontinuous recrystallization is the predominant restoration mechanism within this temperature range. At $700^{\circ} \mathrm{C}(973 \mathrm{~K})$, where normal grain growth takes place, all grains are equiaxed and display very low GOS values.

Figure 6 shows the misorientation angle distribution histograms for samples annealed for $1 \mathrm{~h}$ at $400^{\circ} \mathrm{C}(673 \mathrm{~K})$, $550^{\circ} \mathrm{C}(823 \mathrm{~K})$, and $700^{\circ} \mathrm{C}(973 \mathrm{~K})$. The corresponding percentages of HABs are $44 \%, 59 \%$ and $77 \%$, respectively. These histograms also reveal that the volume fraction of low angle boundaries decreased with annealing. For comparison, the Mackenzie plot, representing the misorientation values of ideal randomly-textured polycrystals ${ }^{36}$, is also plotted. It is worth mentioning that misorientation angle distributions do not take into account boundaries with misorientations below $2^{\circ}$ due to intrinsic limitations of the EBSD technique. These boundaries can be only accounted for in a more precise manner by transmission electron microscopy (TEM).

Table 2. Mean spacing among HABs and corresponding grain aspect ratio as a function of the annealing temperature taken from EBSD data (holding time is 1 hour) (ED: Extrusion direction; HAB: High angle grain boundaries).

\begin{tabular}{cccc}
\hline Annealing temperature $\left({ }^{\circ} \mathrm{C} / \mathrm{K}\right)$ & Parallel to the $\mathrm{ED}(\mu \mathrm{m})$ & Perpendicular to the $\mathrm{ED}(\mu \mathrm{m})$ & Grain aspect ratio \\
\hline $400 / 673$ & $2.4 \pm 1.6$ & $0.4 \pm 0.05$ & 6.0 \\
$500 / 773$ & $2.1 \pm 0.4$ & $0.3 \pm 0.03$ & 7.0 \\
$550 / 823$ & $3.9 \pm 0.7$ & $1.4 \pm 0.12$ & 2.8 \\
$600 / 873$ & $8.0 \pm 0.7$ & $6.8 \pm 0.46$ & 1.2 \\
$700 / 973$ & $8.2 \pm 1.0$ & $8.1 \pm 1.4$ & 1.0 \\
$800 / 1073$ & $19.7 \pm 3.8$ & $21.9 \pm 6.0$ & 1.1 \\
$900 / 1173$ & $44.4 \pm 6.9$ & $48.6 \pm 8.7$ & 1.1 \\
\hline
\end{tabular}






a)



c)

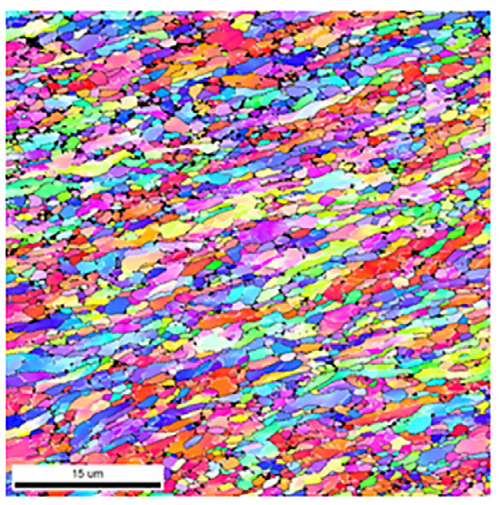

b)

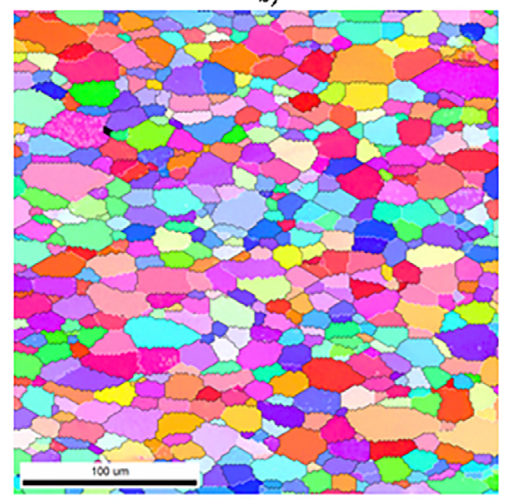

d)

Figure 3. IPF maps of the ED-ND sections of samples annealed at: (a) $400^{\circ} \mathrm{C}(673 \mathrm{~K})$, (b) $500^{\circ} \mathrm{C}$ $(773 \mathrm{~K}),(\mathrm{c}) 550^{\circ} \mathrm{C}(823 \mathrm{~K})$ and $(\mathrm{d}) 700^{\circ} \mathrm{C}(973 \mathrm{~K})$. Black lines mark high angle boundaries (> $15^{\circ}$ ). Low angle boundaries are indicated by white lines (ED: Extrusion direction; ND: normal direction). Notice the changes in the scale bar.

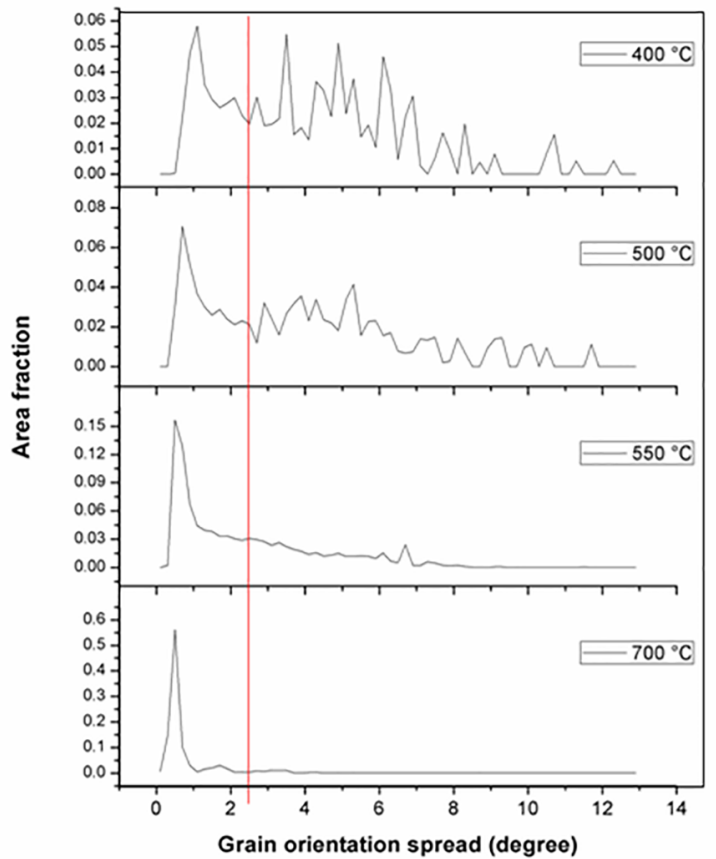

Figure 4. Grain orientation spread (GOS) distributions of ECAPprocessed niobium samples annealed at several temperatures. The red line at $2.5^{\circ}$ marks the threshold between recovered and recrystallized grains.

\subsection{Texture evolution}

The microtexture of ECAP-processed niobium was determined in the as-deformed and annealed states. The evolution of texture during annealing can be analyzed by comparing the respective pole figures, as shown in Figure 7. The intensities are rather similar (about 5 times random) in the annealed condition. The cube component is predominant in the deformed state (ED-ND section). This component is still present after annealing at $550^{\circ} \mathrm{C}(823 \mathrm{~K})$ for $1 \mathrm{~h}$ and after annealing at $600^{\circ} \mathrm{C}(873 \mathrm{~K})$ and $700^{\circ} \mathrm{C}(973 \mathrm{~K})$ for 1 $\mathrm{h}$ it is replaced by other components where grain growth becomes evident, especially at $700^{\circ} \mathrm{C}(973 \mathrm{~K})$.

We focus our analysis on $550^{\circ} \mathrm{C}(823 \mathrm{~K})$ where discontinuous recrystallization becomes significant and where the first recrystallized grains appear. A detailed view of the texture components in the specimen annealed at $550^{\circ} \mathrm{C}(823 \mathrm{~K})$ for $1 \mathrm{~h}$ is shown in Figure 8 . Notice that the cube component inherited from the deformed state prevails in the unrecrystallized areas ${ }^{37,38}$. In order to better understand these results, the recrystallized grains were highlighted from the recovered matrix by using a criterion based on the confidence index (CI) from the EBSD data. The average $\mathrm{CI}$ of the orientation map shown in Figure 8 




a)

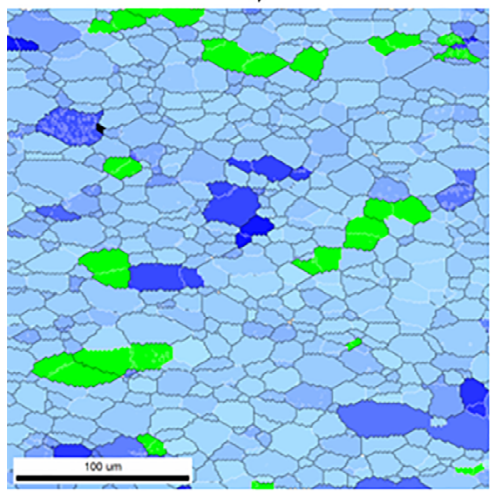

c)
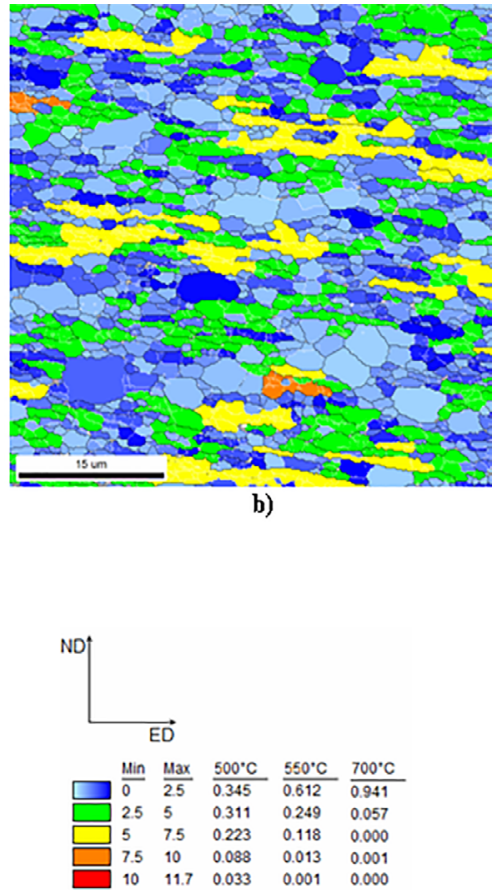

Figure 5. Grain orientation spread (GOS) maps of the ED-ND sections of samples annealed at: (a) $500^{\circ} \mathrm{C}(773 \mathrm{~K})$, (b) $550^{\circ} \mathrm{C}(823 \mathrm{~K})$, (c) $700^{\circ} \mathrm{C}(973 \mathrm{~K})$. (ED: Extrusion direction; ND: normal direction). Notice the changes in the scale bar.



Figure 6. Comparison between the misorientation distribution histograms in niobium single crystal deformed by 8 ECAP passes and annealed for 1 hour at $400^{\circ} \mathrm{C}(673 \mathrm{~K}), 550^{\circ} \mathrm{C}(823 \mathrm{~K})$, and $700^{\circ} \mathrm{C}$ $(973 \mathrm{~K})$. The Mackenzie distribution is also depicted (dashed line).

is 0.34 . The confidence index gives a numerical measure of pattern indexing quality, i.e. it quantifies the reliability of the indexing solution proposed by the analysis software. About 250 recrystallized grains (points with $\mathrm{CI}>0.75$ ) were selected from the orientation map presented in Figure 8 and their orientation is shown in the pole figure in Figure $9 b$. Similar results can be obtained by using the GOS $<2.5^{\circ}$ criterion. Even loosing a few grains with this procedure, most of the recrystallized grains were accounted for. Cube and other minor components are present. The use of lower values of CI did not allow us to make a perfect separation since the $\mathrm{CI}$ found in many points in the recovered matrix was quite high. Using a similar procedure, the orientation of the recovered areas was also determined (Figure 9a). From the corresponding (001) pole figure, it can be seen that the recovered matrix is deviated about $10^{\circ}$ from the ideal cube component.

By comparing both pole figures (Figure 9) it is possible to observe that the microtexture of the recrystallized grains differs only slightly from the orientation of the recovered matrix. Other minor components did appear in the annealed microstructure. This observation can be understood from the fact that most cube grains are abutting on other near-cube grains because of the strong cube fiber texture. The interfaces between both grains hence have low mobility. Apparently some minor components present in the deformed structure having a high angle boundary with a high probability of being surrounded by at least one cube grain appeared, forming new texture components. From these data it is not entirely clear why the cube texture component was consumed by inward growing minority texture components instead of growing outbound, sharpening the cube texture component. 
a)
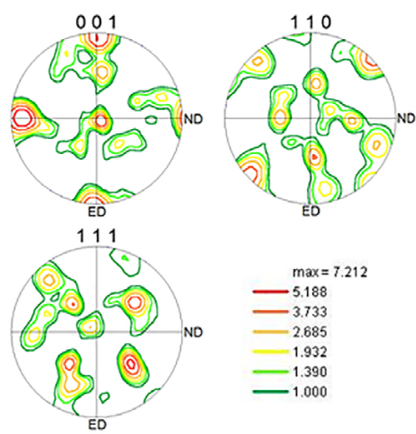

c)



EO
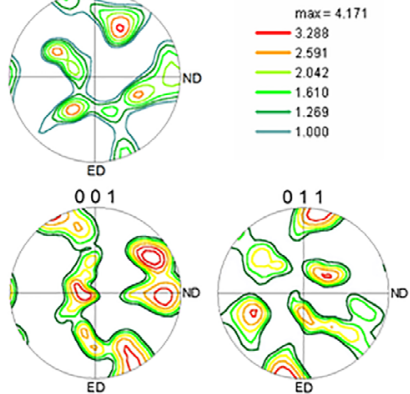

111


d)

Figure 7. Contoured pole figures showing the evolution of microtexture in niobium single crystal deformed by 8 ECAP passes and annealed for 1 hour at several temperatures: (a) as-deformed state; (b) $550^{\circ} \mathrm{C}(823 \mathrm{~K})$; (c) $600^{\circ} \mathrm{C}(873 \mathrm{~K})$ and (d) $700^{\circ} \mathrm{C}(973 \mathrm{~K})$. EBSD measurements were carried out in ED-ND sections (ED: Extrusion direction; ND: normal direction).

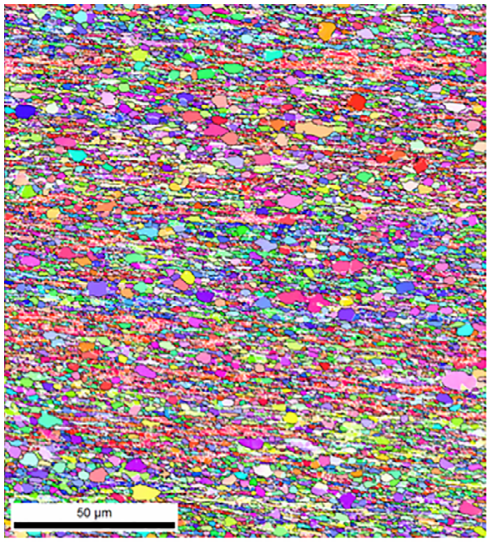

a)

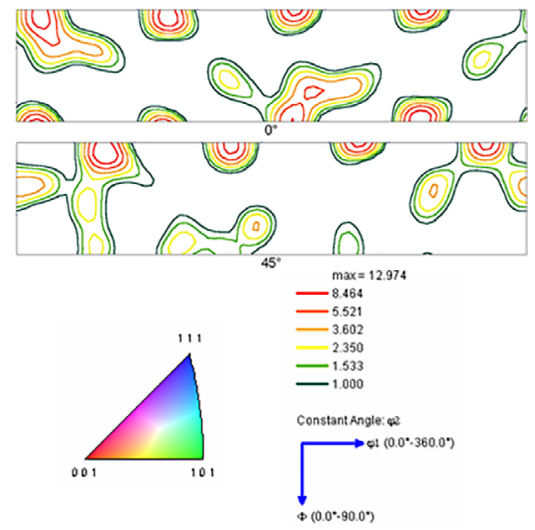

b)

Figure 8. (a) Orientation map (ED-ND section) and (b) ODF sections $\left(\varphi_{2}=0^{\circ}\right.$ and $\left.\varphi_{2}=45^{\circ}\right)$ of niobium after 8 ECAP passes followed by annealing at $550 \mathrm{oC}(823 \mathrm{~K})$ for 1 hour. (ED: Extrusion direction; ND: normal direction).

One possible explanation could be that there is an equal chance to go in both ways, but if the boundary consumes the cube grain, there is a high probability that the next grain that it will encounter is again a cube grain, so a new HAB is formed and the minor component has a size advantage and proceeds growing. On the other hand, if the boundary consumes the minor component (growth of the cube grains), there is also a high probability that the next grain is again a cube one and hence a LAB is formed and further growth is prevented or slowed down (orientation pinning). This might explain why the cube component weakens and other minor components appear when annealing at higher temperatures, that is $>550^{\circ} \mathrm{C}(823 \mathrm{~K})$.

After annealing at $700^{\circ} \mathrm{C}(973 \mathrm{~K})$ a different situation is observed, i.e. the cube texture after ECAP is replaced by another texture component rotating towards $\{001\}<110>$ (rotated cube). Figure $3 \mathrm{~d}$ reveals the occurrence of normal grain growth. Once more, the net effect is the growth of some minority texture components during coarsening. The new texture at $700^{\circ} \mathrm{C}(973 \mathrm{~K})$ can be explained in the sense that the precise orientation found at $700^{\circ} \mathrm{C}(973 \mathrm{~K})$ is essentially determined by the appearance of more randomly 

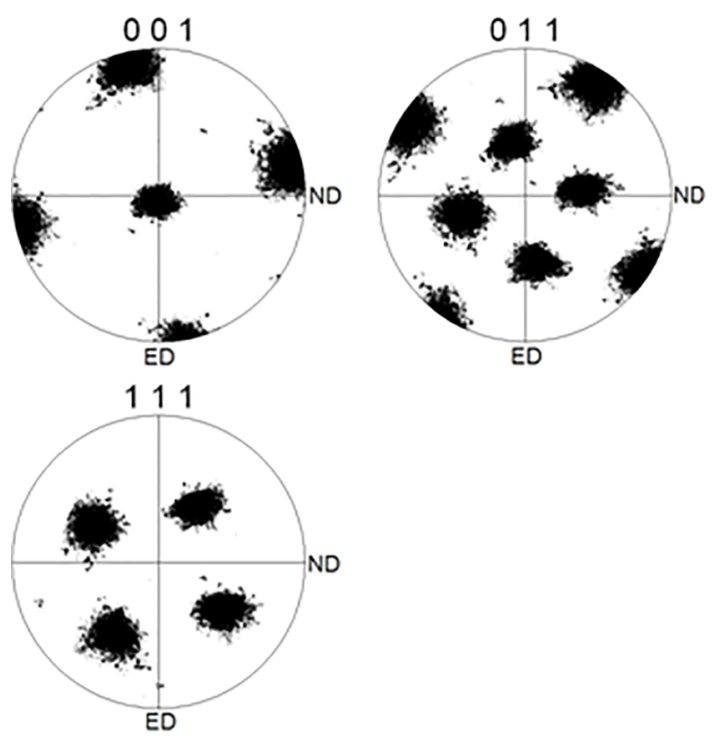

a)
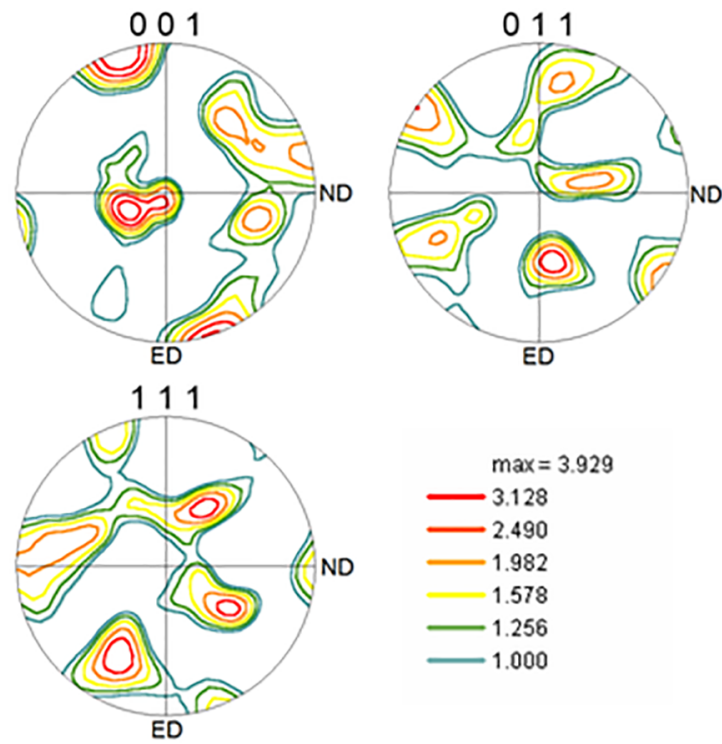

b)

Figure 9. Pole figures corresponding to the orientation map shown in Fig. 8: (a) recovered matrix and (b) recrystallized grains (CI $>0.75)$.

oriented new grains; i.e. the prior minor texture component which were inherited from the deformed structure replace the initial cube texture.

Full understanding of the recrystallization texture in this material is challenging. ECAP-processed materials can display pronounced texture heterogeneity, i.e., texture variations from one position to another in the processed material ${ }^{22,39-41}$. These variations have distinct causes such as friction (die-workpiece), massive shear banding and grain orientation effects ${ }^{42}$. Also, comparison between the texture components found before and after recrystallization annealing in this material has to take also into account statistical effects, i.e. the small number of grains/crystallites used to build up the pole figures.

\section{Conclusions}

The microstructural stability of [211]-oriented niobium single crystal deformed by 8 ECAP passes (route $\mathrm{B}_{\mathrm{c}}$ ) during isothermal annealing up to $900^{\circ} \mathrm{C}(1173 \mathrm{~K})$ was investigated. The microstructure of the as-deformed specimen consists of fine crystallites arranged in a lamellar structure with sizes smaller than $1 \mu \mathrm{m}$ and an average grain aspect ratio above 6. After 8 ECAP passes a sharp cube texture develops in the deformed state for this particular crystal orientation. High-resolution EBSD was used to follow the changes in texture and mesotexture after annealing in vacuum in the temperature range $400-900^{\circ} \mathrm{C}(673-1173 \mathrm{~K})$. Significant changes in values of both the volume fraction of high angle boundaries and Vickers hardness show that primary (discontinuous) recrystallization is the main softening mechanism with a maximum rate at about $550^{\circ} \mathrm{C}(823 \mathrm{~K})$.
Above $700^{\circ} \mathrm{C}(973 \mathrm{~K})$, normal grain growth prevails. The cube texture after ECAP processing is replaced by another texture component rotating towards $\{001\}<110>$ (rotated cube) during grain growth.

\section{Acknowledgments}

Authors are thankful to FAPESP (Brazil) for the support provided by Grant 04/14875-0. HRZS is CNPq Fellow (306050/2013-7). The kind assistance of Katja Angenendt (MPIE) with FEG-SEM-EBSD measurements is greatly appreciated.

\section{References}

1. Ferrasse S, Segal VM, Alford F, Kardokus J, Strothers S. Scale up and application of equal-channel angular extrusion for the electronics and aerospace industries. Materials Science and Engineering: A. 2008;493(1-2):130-140.

2. Medvedev A, Ng HP, Lapovok R, Estrin Y, Lowe TC, Anumalasetty VN. Comparison of laboratory-scale and industrial-scale equal channel angular pressing of commercial purity titanium. Materials Letters. 2015;145:308-311.

3. Azushima A, Kopp R, Korhonen A, Yang DY, Micari F, Lahoti $\mathrm{GD}$, et al. Severe plastic deformation (SPD) processes for metals. CIRP Annals - Manufacturing Technology. 2008;57(2):716-735.

4. Lowe TC. Metals and alloys nanostructured by severe plastic deformation: commercialization pathways. JOM - Journal of The Minerals, Metals \& Materials Society. 2006;58(4):28-32.

5. Li S, Beyerlein IJ. Modelling texture evolution in equal channel angular extrusion of bcc materials: effects of processing route and initial texture. Modelling and Simulation in Materials Science and Engineering. 2005;13(4):509. 
6. Segal VM. Materials processing by simple shear. Materials Science and Engineering: A. 1995;197(2):157-164.

7. Zhu YT, Lowe TC. Observations and issues on mechanisms of grain refinement during ECAP process. Materials Science and Engineering: A. 2000;291(1-2):46-53.

8. Valiev RZ, Langdon TG. Principles of equal-channel angular pressing as a processing tool for grain refinement. Progress in Materials Science. 2006;51(7):881-981.

9. Huang HW, Chang L, Kao PW, Chang CP. Effect of die angle on the deformation texture of copper processed by equal channel angular extrusion. Materials Science and Engineering: $A$. 2001;307(1-2):113-118

10. Beyerlein IJ, Lebensohn RA, Tomé CN. Modeling texture and microstructural evolution in the equal channel angular extrusion process. Materials Science and Engineering: $A$. 2003;345(1-2):122-138.

11. Tóth LS, Massion RA, Germain L, Baik SC, Suwas S. Analysis of texture evolution in equal channel angular extrusion of copper using a new flow field. Acta Materialia. 2004;52(7):1885-1898.

12. Hayes JS, Keyte R, Prangnell PB. Effect of grain size on tensile behaviour of a submicron grained $\mathrm{Al}-3 \mathrm{wt}-\% \mathrm{Mg}$ alloy produced by severe deformation. Materials Science and Technology. 2000;16(11-12):1259-1263.

13. Valiev RZ, Islamgaliev RK, Alexandrov IV. Bulk nanostructured materials from severe plastic deformation. Progress in Materials Science. 2000;45(2):103-189.

14. Wang ZC, Prangnell PB. Microstructure refinement and mechanical properties of severely deformed Al-Mg-Li alloys. Materials Science and Engineering: A. 2002;328(1-2):87-97.

15. Prangnell PB, Hayes JS, Bowen JR, Apps PJ, Bate PS. Continuous recrystallisation of lamellar deformation structures produced by severe deformation. Acta Materialia. 2004;52(11):3193-3206.

16. Sandim HRZ, Raabe D. An EBSD study on orientation effects during recrystallization of coarse-grained niobium. Materials Science Forum. 2004;467-470:519-524.

17. Humphreys FJ, Prangnell PB, Bowen JR, Gholinia A, Harris C. Developing stable fine-grain microstructures by large strain deformation. Philosophical Transactions of the Royal Society A. 1999;357(1756):1663-1681.

18. Messemaeker JD, Verlinden B, Humbeeck JV. Structural evolution of IF steel during annealing after ECAP. Materials Science Forum. 2004;467-470:1295-1300.

19. Mathaudhu SN, Barber RE, Hartwig KT. Microstructural refinement of tantalum for $\mathrm{Nb}_{3} \mathrm{Sn}$ superconductor diffusion barriers. IEEE Transactions on Applied Superconductivity. 2005;15(2):3434-3437.

20. Mathaudhu SN, Hartwig KT. Grain refinement and recrystallization of heavily worked tantalum. Materials Science and Engineering: A. 2006;426(1-2):128-142.

21. Hazra SS, Pereloma EV, Gazder AA. Microstructure and mechanical properties after annealing of equal-channel angular pressed interstitial-free steel. Acta Materialia. 2011;59(10):4015-4029.

22. Sandim HRZ, Bolmaro RE, Renzetti RA, Sandim MJR, Hartwig KT, Vogel SC, et al. Texture Evolution as Determined by In situ Neutron Diffraction During Annealing of Iron Deformed by
Equal Channel Angular Pressing. Metallurgical and Materials Transactions A. 2014;45(10):4235-4246.

23. Bernardi HH, Sandim HRZ, Verlinden B, Raabe D. Recrystallization of niobium single crystals deformed by ECAE. Materials Science Forum. 2007;558-559:125-130.

24. Sandim HRZ, Bernardi HH, Verlinden B, Raabe D. Equal channel angular extrusion of niobium single crystals. Materials Science and Engineering: A. 2007;467(1-2):44-52.

25. Prangnell PB, Bowen JR, Gholinia A. The formation of submicron and nanocrystalline grain structure by severe deformation. In: Proceedings of the $22^{\text {nd }}$ Risø International Symposium on Materials Science; 2001 Sep 3-7; Risø, Denmark. National Laboratory; 2001. p. 105-126.

26. Etter AL, Baudin T, Rey C, Penelle R. Microstructural and textural characterization of copper processed by ECAE. Materials Characterization. 2006;56(1):19-25.

27. Reihanian M, Ebrahimi R. Moshksar MM, Terada D, Tsuji N. Microstructure quantification and correlation with flow stress of ultrafine grained commercially pure $\mathrm{Al}$ fabricated by equal channel angular pressing (ECAP). Materials Characterization . 2008;59(9):1312-1323.

28. Pan Z, Xu F, Mathaudhu SN, Kecskes LJ, Yin WH, Zhang XY, et al. Microstructural evolution and mechanical properties of niobium processed by equal channel angular extrusion up to 24 passes. Acta Materialia. 2012;60(5):2310-2323.

29. Jazaeri H, Humphreys FJ. Quantifying recrystallization by electron backscatter diffraction. Journal of Microscopy. 2004;213(Pt 3):241-246.

30. Raabe D, Schlenkert G, Weisshaupt H, Lücke K. Texture and microstructure of rolled and annealed tantalum. Materials Science and Technology. 1994;10(4):299-305.

31. Cao Y, Di H, Zhang J, Zhang J, Ma T, Misra RDK. An electron backscattered diffraction study on the dynamic recrystallization behavior of a nickel-chromium alloy $(800 \mathrm{H})$ during hot deformation. Materials Science and Engineering: A. 2013;585:71-85.

32. Vignal V, Ba D, Zhang H, Herbst F, Manchet SL. Influence of the grain orientation spread on the pitting corrosion resistance of duplex stainless steels using electron backscatter diffraction and critical pitting temperature test at the microscale. Corrosion Science. 2013;68:275-278.

33. Sheng H, Sun Z, Uytdenhouwen I, Oost GV, Vleugels J. Temperature and deformation effect on the low and high angle grain boundary structure of a double forged pure tungsten. International Journal of Refractory Metals and Hard Materials. 2015;50:184-190.

34. Cao Y, Di H. Research on the hot deformation behavior of a $\mathrm{Fe}-\mathrm{Ni}-\mathrm{Cr}$ alloy $(800 \mathrm{H})$ at temperatures above $1000^{\circ} \mathrm{C}$. Journal of Nuclear Materials. 2015;465:104-115.

35. Zaefferer S, Romano P, Friedel F. EBSD as a tool to identify and quantify bainite and ferrite in low-alloyed Al-TRIP steels. Journal of Microscopy. 2008;230(3):499-508.

36. Mackenzie JK. Second paper on statistics associated with the random disorientation of cubes. Biometrika. 1958;45(1-2):229-240. 
37. Raabe D, Lücke K. Rolling textures of niobium and molybdenum. Zeitschrift für Metallkunde. 1994;85(5):302-306.

38. Raabe D, Ball J, Gottstein G. Rolling textures of a $\mathrm{Cu}-20 \% \mathrm{Nb}$ composite. Scripta Metallurgica et Materialia. 1992;27(2):211-216.

39. Skrotzki W, Scheerbaum N, Oertel CG, Arruffat-Massion R, Suwas S, Tóth LS. Microstructure and texture gradient in copper deformed by equal channel angular pressing. Acta Materialia. 2007;55(6):2013-2024.

40. Skrotzki W, Tränkner C, Chulist R, Beausir B, Suwas S, Tóth LS. Texture heterogeneity in ECAP deformed copper. Solid State Phenomena. 2010;160:47-54.
41. Li S, Beyerlein IJ, Necker CT, Alexander DJ, Bourke M. Heterogeneity of deformation texture in equal channel angular extrusion of copper. Acta Materialia. 2004;52(16):4859-4875.

42. Jia N, Roters F, Eisenlohr P, Raabe D, Zhao X. Simulation of shear banding in heterophase co-deformation: Example of plane strain compressed $\mathrm{Cu}-\mathrm{Ag}$ and $\mathrm{Cu}-\mathrm{Nb}$ metal matrix composites. Acta Materialia. 2013;61(12):4591-4606. 